\title{
RAWLS, HEGEL E O LIBERALISMO DA LIBERDADE
}

Cesar Augusto Ramos*

SÍNTESE - Este artigo procura examinar a avaliação de Rawls acerca de alguns aspectos da filosofia política de Hegel. Rawls interpreta Hegel como um liberal de mente moderadamente reformista, e seu liberalismo é um importante exemplar na história do liberalismo da liberdade. Pretendemos, primeiramente, examinar o estatuto do liberalismo de Hegel, particularmente a questão da liberdade individual. Em segundo lugar, apresentamos alguns aspectos do entendimento de Rawls acerca deste liberalismo. A plausibilidade da filosofia política de Hegel é questionada, quando Rawls analisa a sua possível contribuição à luz do liberalismo político.

PALAVRAS-CHAVE - Liberalismo. Liberdade. Liberalismo politico. Hegelianismo.
ABSTRACT - This article seeks to examine Ralws's evaluation about some features of Hegel's political philosophy. Rawls interprets Hegel as a liberal, with a moderately reforming mind, and his liberalism is an important exemplar in the history of liberalism of freedom. We intend, first, to examine Hegel's liberalism statute, particularly the individual freedom issue. Second, we present some aspects of Rawls's understanding about this liberalism. Hegel's political philosophy plausibility is questioned, when Rawls analyses his possible contribution in the light of political liberalism.

KEY WORDS - Liberalism. Freedom. Political liberalism. Hegelianism.

\section{Introdução}

Hegel é considerado um filósofo, cujas teses sobre o Estado, a sociedade e a liberdade individual têm sido objeto de suspeição, se interpretadas do ponto de vista da tradição do pensamento liberal, desde os clássicos até o liberalismo político de J. Rawls. A despeito da posição de Hegel em relação ao tema da liberdade constituir objeto de investigação já suficientemente explorado na literatura hegeliana, permanece a questão: foi ele um pensador sensível ao princípio liberal da liberdade do indivíduo e dos direitos individuais, ou negou esse princípio em benefício do Estado?

Diante dessa questão, a leitura da filosofia política de Hegel oferece duas interpretações. Aquela que considera Hegel como pensador antiliberal identifica a sua filosofia política como autoritária, estatizante ou, na melhor das hipóteses,

Doutor. Professor da PUCPR (Pontifícia Universidade do Paraná).

\begin{tabular}{|l|l|l|l|l|l|}
\hline VERITAS & Porto Alegre & v. 50 & n. 1 & Março 2005 & p. 41-65 \\
\hline
\end{tabular}


conservadora. Esta interpretação toma por base algumas passagens do texto hegeliano, nelas vendo o comprometimento da liberdade individual, face às alegadas inclinações favoráveis ao autoritarismo que estariam amparando a filosofia política do pensador alemão. ${ }^{1}$

Uma outra interpretação, compatível com algumas teses do liberalismo, consiste em avaliar o hegelianismo político como uma doutrina da liberdade. Estudos mais recentes da obra política de Hegel demonstraram a improcedência das acusações, segundo as quais o filósofo teria negado a liberdade individual e os direitos da pessoa, procurando confirmar a tese de que a filosofia política hegeliana pode ser vista como uma teoria, cuja preocupação principal gira em torno do tema da liberdade, tanto do ponto de vista institucional como individual. ${ }^{2}$

Se esta última interpretação parece ser a mais plausível, a questão fica particularmente desafiadora no momento em que algumas concepções do chamado liberalismo hegeliano são estimadas em relação ao liberalismo político de J. Rawls, mormente quando a sua teoria insere-se na linha de pensamento hostil às idéias metafísicas que amparam o organicismo e o holismo na filosofia política, alguns de inspiração hegeliana. Assim, o sistema hegeliano - com sua linguagem abstrusa envolta de idealismo, com o seu método especulativo de apelo às noções metafísicas, consideradas arcaicas, de totalidade, Espírito absoluto, e a sua visão lógico-

De fato, algumas afirmações da Filosofia do Direito de Hegel dão margem a esse tipo de interpretação. Por exemplo: "O Estado é o absoluto e imóvel fim último [...] este fim último tem um direito superior ao indivíduo cujo supremo dever é ser membro do Estado" (§ 258). "As determinações da vontade individual são levadas por meio do Estado a uma existência objetiva e somente por seu intermédio alcançam sua verdade e sua realização. O Estado é a única condição para conseguir o fim e o bem-estar particulares" (§ 261, ad.). A acusação de que Hegel glorifica o Estado foi iniciada no século passado por R. Haym com a sua obra Hegel und seine Zeit. Outros autores como K. Popper (The Open Society and its Enemies) seguiram a mesma linha, colocando o hegelianismo político na trilha daqueles que propugnaram um Estado totalitário, tribal. Popper estabelece a correlação teórica e histórica entre a visão holista da política, o totalitarismo e o anti-individualismo. Hegel seria o elo que faltava entre Platão e o "totalitarismo moderno". M. Bienenstock observa que "a assimilação da filosofia política hegeliana à glorificação do Machtstaat, de um Estado de poder protobismarckiano está tradicionalmente associada, na literatura sobre Hegel, aos nomes do célebre historiador alemão F. Meinecke - Weltbürgertum und Nationalstaat ... 1911 - e H. Heller - Hegel und die nationale Machtsgedanke in Deutschland. ... 1921." (Politique du jeune Hegel. Iéna 1801-1806. Paris: PUF, 1992, p. 45).

2 "O hegelianismo político foi, deste modo, interpretado como a filosofia que diviniza o Estado em diversos matizes: ora como glorificação do regime político prussiano (H. Heller, F. Rosenzweig, T. Litt, J. Dewey, L.T. Hobhouse, S. Hook, J. Plamenatz), ora como ideólogo do Estado fechado e totalitário inimigo da sociedade aberta das democracias ocidentais (K. Popper), ora como inspirador da ideologia de um poder mistificador e salvador (E. Topitsch), ora como mentor do mito do Estado forte (E. Cassirer). A reação contra essa interpretação ocorreu precisamente a partir do resgate do princípio da liberdade individual ou subjetiva na filosofia hegeliana. Hegel passou a ser considerado como pensador da moderna sociedade politicamente organizada segundo os elementos do Estado de direito, e organizado segundo o princípio da liberdade. Essa interpretação, chamada de liberal, manifestou-se na França (E. Weil, E. Fleischmann, J. D’Hondt, F. Grégoire, J-C. Pinson, H. Denis, J-F Kervégan, e outros), na Inglaterra e nos Estados Unidos da América (T.M. Knox, J.N. Findlay, W. Kaufmann, Z. Pelczynski, S. Avineri, C. Taylor), na Itália (D. Losurdo), na Alemanha (J. Ritter, G. Rohrmoser. R. Maurer, M. Riedel, O. Marquard, H. Lübbe)." (Cf. RAMOS, C. A. Hegel e o princípio da liberdade individual do liberalismo. In: Cadernos de Ética e Filosofia Política, 4, p. 116,117, 2002, São Paulo.) 
especulativa da realidade - não poderia oferecer nenhum atrativo às teses do liberalismo político de Rawls, sobretudo quando o pensador da Filosofia do Direito foi um crítico do contratualismo, e sua relação com os princípios liberais pode ser considerada bastante suspeita por alguns intérpretes.

Contudo, ao alinhar o hegelianismo político àquelas teorias que têm por objeto a investigação sobre o tema da liberdade, Rawls anuncia o seu propósito dizendo: "eu interpreto Hegel como uma liberal de mente reformista moderadamente progressista, e eu vejo seu liberalismo como um importante exemplar na história da filosofia política e moral do liberalismo da liberdade". ${ }^{3}$ Esclarece, ainda, que este liberalismo (Kant e J. S. Mill são outros teóricos perfilados nessa mesma linha) é uma doutrina cujos primeiros princípios são aqueles definidos pela liberdade política e cívica, os quais têm prioridade sobre outros preceitos que poderiam ser evocados. "A tradição do liberalismo da liberdade parte pelo menos da Reforma e dá especial prioridade para certas liberdades básicas: liberdade de consciência e liberdade de pensamento, liberdade das pessoas e da livre escolha da vocação liberdade da escravidão e da servidão - para mencionar vários casos básicos." ${ }^{4}$

Ao considerar o liberalismo de Hegel como um liberalismo da liberdade, Rawls concede a possibilidade de se entender a liberdade na perspectiva hegeliana, ou seja, de forma estrutural, vinculada a um sistema de instituições sociais e políticas que garantem e tornam possível a liberdade dos cidadãos, justificando, assim, a presença do Estado como momento mais alto dessa liberdade. A incorporação da vontade livre nas instituições sociais e políticas do Estado moderno é avaliada por Rawls como "uma das mais importantes contribuições [de Hegel] para a filosofia moral e política". ${ }^{5}$ Contudo, essa concepção de liberdade está longe de associar a Filosofia do Direito ao propósito de "justificação do estado prussiano em 1820 ou mais tarde", ou ao "imperialismo germânico e aos Nazis". ${ }^{6}$ Assim, Rawls inclina-se para aqueles intérpretes que defendem a tese de "Hegel foi um liberal moderado e defensor do estado constitucional moderno", apesar da sua força constituinte no sistema da Sittlichkeit, e é justamente nesse ponto onde Hegel "parece se afastar do liberalismo tradicional". ?

Se a inclusão de Hegel ao lado de diversos autores que operam com o conceito de liberdade é bastante alargada, permitindo a reunião de todos eles sob a etiqueta do liberalismo da liberdade, no que tocante à aceitação e à legitimidade das instituições políticas pelos cidadãos, outras possibilidades são propostas por Rawls para a classificação dos diversos liberalismos: o liberalismo de "justifica-

\footnotetext{
RAWLS, J. Lectures on the History of Moral Philosophy, Cambridge: Harvard University Press, 2000, p. 330.

Idem, p. 366.

Idem, p. 331.

Idem, p. 352.

Apesar da recepção positiva de Hegel na linha do liberalismo da liberdade, Rawls avalia a filosofia política de Hegel ainda insuficiente se comparada com as exigências de um conceito pleno de uma teoria liberal da política, tal como ele a expõe no artigo "A idéia de um consenso por justaposição". (Cf. RAWLS, J. Justiça e Democracia. Trad. Irene A. Paternot, São Paulo: Martins Fontes, 2000, p. 277.)
} 
ção", o de modus vivendi, o liberalismo ético e o liberalismo político, este último defendido pelo autor.

O liberalismo de Rousseau e de Hegel pode ser considerado como de "justificação" porque adota o ponto de vista da legitimação das instituições políticas, a partir de uma concepção moral convergente de um bem comum, assumida pelo conjunto dos cidadãos reunidos em torno de uma vontade política comunitária. O liberalismo de modus vivendi, que remonta ao hobbesiano, é "garantido pela convergência de interesses individuais ou de interesses de grupo, coordenado e equilibrado por um dispositivo constitucional bem concebido." ${ }^{\prime 8}$ Segundo Rawls, esse tipo de liberalismo não pode garantir uma "unidade social persistente". ${ }^{9}$ O liberalismo ético, como o de Kant e de Mill, está baseado em "doutrinas morais gerais e abrangentes", legitimando as instituições sociais e políticas pelo princípio moral da autonomia (Kant), ou pelo ideal do individualismo (Mill), ambos amplamente compartidos pelos indivíduos de uma determinada sociedade. O problema desse liberalismo é que ele "não pode produzir um acordo suficiente" por não satisfazer as exigências de uma concepção política da justiça.

O liberalismo político de Rawls é "verificacionista" no sentido de que a legitimidade das instituições políticas ocorre pela razão pública de verificação organizada em torno de uma concepção política de justiça: "o papel público de uma concepção da justiça mutuamente admitida é precisar um ponto de vista a partir do qual todos os cidadãos possam verificar, uns perante os outros, se suas instituições são ou não são justas. Esse ponto de vista lhes proporciona essa verificação ao precisar as razões válidas e suficientes com as quais estão acordes e que são definidas como tais por essa concepção." ${ }^{10}$ Uma concepção política da justiça, produzida através de um consenso por justaposição (overlapping consensus), é compatível com exigências indispensáveis de uma sociedade liberal, como a existência do pluralismo e de uma razão pública livre. O liberalismo político, além de ser "verificacionista" é, também, um liberalismo da liberdade, no sentido de que, uma vez asseguradas as liberdades básicas, os indivíduos podem coexistir com diferentes ideais morais e políticos, preservando o pluralismo das concepções morais abrangentes em vigor numa sociedade.

Se há divergências quanto à forma pela qual as instituições sociais e políticas podem ser legitimadas - o liberalismo político afasta-se da idéia rousseauístahegeliana da integração comunitária das vontades particulares na figura do valor republicano da cidadania -, o inusitado é que a filosofia política de Hegel é classificada por Rawls na linha de pensamento do liberalismo da liberdade.

Como é possível aproximar esses dois autores, e quais as conseqüências que essa proximidade pode trazer para o liberalismo político de Rawls? Essa questão torna-se deveras suspicaz quando um dos objetivos desse liberalismo consiste em fornecer uma análise convincente dos direitos e das liberdades básicas, e consig-

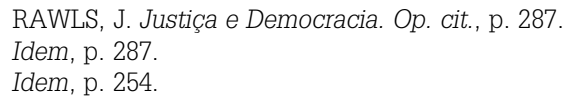


nar a sua prioridade em princípios de justiça em uma perspectiva nitidamente alinhada com o pensamento político liberal de ênfase aos direitos e às liberdades individuais, atributos que devem ser tomados como realidades primárias, sobre as quais são erigidas as instituições sociais e políticas, cuja legitimidade nasce do consenso "verificacionista" baseado numa concepção pública de justiça.

A perspectiva de comparação entre os dois pensadores não tem por objetivo sopesar duas formas possíveis de pensamento político, com o objetivo de verificar qual delas é a mais correta, mas melhor avaliar o liberalismo político individualista de Rawls e o "comunitarismo" de Hegel, o qual não nega o princípio da liberdade e os direitos individuais, pois fundamenta-os na perspectiva do substancialismo ético que tem por base a "Idéia" de liberdade. De um lado, a análise da natureza do liberalismo hegelinano é de grande importância para dimensionar o estatuto filosófico de uma teoria política que tem na liberdade o objeto principal de investigação; de outro lado, a leitura "hegeliana" de Rawls estimula uma compreensão mais adequada do seu liberalismo político, esclarecendo possíveis correções do liberalismo rawlsiano, motivadas pelas críticas comunitaristas, algumas de inspiração hegeliana.

Vamos analisar a relação de Rawls com Hegel em torno do chamado liberalismo da liberdade em duas partes. De início, e grosso modo, pretendemos apontar a relação de Hegel com o liberalismo clássico, particularmente a questão da liberdade do indivíduo, central para ambos, procurando avaliar com mais justeza o liberalismo hegeliano. ${ }^{11}$ Em seguida, vamos expor alguns aspectos da leitura de Rawls desse liberalismo, a qual pretende analisar as contribuições hegelianas, interpretando a sua pertinência e plausibilidade sob a ótica do liberalismo político. Apesar das diferenças, o diálogo crítico com Hegel pode ajudar a esclarecer, de forma mais adequada, o déficit comunitarista da teoria rawlsiana. Finalmente, apresentamos algumas considerações conclusivas, dentre elas a noção hegeliana da reconciliação e o seu importante papel, reconhecido por Rawls, para a filosofia política.

\footnotetext{
1 Uma análise mais detalhada sobre as aproximações de Hegel com o liberalismo pode ser encontrada em: RAMOS, C. A. Hegel e o princípio da liberdade individual do liberalismo. In: Cadernos de Ética e Filosofia Politica, 4, São Paulo, 2002; cf. também: LOSURDO, D. Hegel, Marx e a Tradição Liberal. Liberdade, Igualdade, Estado. Trad. Carlo N. Dastoli, São Paulo: Fundação Ed. UNESP, 1998; PINSON, J. C. Hegel, le Droit et le Libéralisme, Paris: PUF, 1989; TAYLOR, C. Hegel's ambiguous legacy for modern liberalism. In: CORNELL, D., ROSENFELD. M. And CARLSON, D. G. (eds.), Hegel and LegalTheory, London: Routledge, 1991. p. 64-77; STILLMANN, P. Hegel's critique of liberal theories of rights. In: The American Political Science Review, vol. 68, 1974, p. 1086-1092.
} 


\section{A recepção crítica de Hegel ao princípio da liberdade individual do liberalismo}

A liberdade individual representa um tema recorrente para a escola do Jusnaturalismo moderno. Compreendida como direito subjetivo, ${ }^{12}$ ela define-se como uma qualidade essencial do indivíduo, um atributo imanente ao sujeito que a detém como uma qualidade (facultas), habilitando-o a agir segundo a sua vontade. Assim considerada, a liberdade dos modernos se define pela natureza humana capturada na sua imanência auto-explicativa, abandonando o modelo teleológico da ética antiga e do Direito Natural clássico.

Com base nestes pressupostos, e segundo padrões teóricos que marcam distinções políticas em autores como Hobbes, Espinosa, Pufendorf, Locke, Rousseau, Kant, Fichte e outros, os filósofos do Jusnaturalismo moderno elaboraram, cada um a seu modo, teorias políticas para explicar a constituição da societas civilis. O elo de ligação de todos sob o epíteto de "Jusnaturalismo" não esconde diferenças entre eles. Mas, determinados temas como o estado de natureza, a questão da igualdade e da liberdade, a finalidade do contrato social, a constituição do Estado, os limites e o alcance do poder político são constantes, e convergem para a questão comum da liberdade dos indivíduos como direito natural.

A preocupação da política consiste em organizar os sujeitos adequadamente na sociedade civil de acordo com as regras racionais do direito. Dessa organização decorre a autoridade política do Estado, "corpo artificial" e fruto da criação dos homens que deve, segundo maior ou menor grau de poder, proteger a liberdade, a propriedade e o bem-estar dos indivíduos. Em oposição à tradição que afirmava que o dever principal do indivíduo é a realização da sua perfeição, possível somente quando ele alcança o seu fim (político) como zoon politikon no seio da comunidade política, para a qual tem deveres, o homem moderno postula direitos, pois sua realidade (individual) é anterior à comunidade.

Para os antigos, o indivíduo é soberano nos assuntos públicos e escravo em todas as relações privadas, observa B. Constant. Para os modernos, a liberdade é um meio para a segurança privada, e as instituições sociais e políticas representam a garantia para a fruição dessa liberdade. "A independência individual é a primeira das necessidades modernas. Em conseqüência, jamais se deve exigir o seu sacrifício para estabelecer a liberdade política". ${ }^{13} \mathrm{Na}$ modernidade, os indivíduos têm direitos que devem ser respeitados por todos, e a liberdade política deve representar a sua defesa. Assim, quanto mais o indivíduo é livre para cuidar dos seus interesses privados, tanto mais a liberdade lhe será preciosa. Daí a necessidade de "ausência" nos assuntos públicos (políticos) e a conseqüente exigência da

\footnotetext{
12 Na afirmação categórica de M. Villey, "o elemento primordial do sistema do direito (tanto positivo como natural), torna-se, doravante, a noção de direito subjetivo[...]" (La formation de la pensée juridique moderne. Paris: Montchretien, 1975, p. 153).

3 CONSTANT, B. De la liberté chez les modernes. Paris: Librairie Générale Française, 1980, p. 506.
} 
representação política. "A liberdade individual - insiste Constant - eis a verdadeira liberdade moderna. A liberdade política é a sua garantia."14

$\mathrm{Na}$ esteira do Jusnaturalismo moderno, o liberalismo clássico declara a liberdade - tanto na versão da "liberdade negativa", entendida como a esfera de ação em que o indivíduo não está impedido de fazer ou deixar de fazer aquilo que ele deseja, como na versão da "liberdade positiva" da autonomia da vontade ${ }^{15}$ - como o princípio básico para a vida privada e social dos indivíduos. Através dela, estes tornam-se agentes conscientes e responsáveis, possuindo direitos e valor ético, independentemente dos outros ou da coletividade. Para o liberalismo, a liberdade individual está desvinculada de qualquer fundamento conceitual externo a ela mesma. Ela tem um valor auto-referente, pois determina-se pela igualdade de todos de possuí-la como um direito (subjetivo), e se realiza pelo interesse pessoal (na propriedade, no trabalho, no livre comércio) que o indivíduo julga ser melhor para si a partir da sua vontade que se explicita na realização do sujeito.

A noção de justiça deve ser entendida como o necessário respeito aos direitos individuais que sustentam os indivíduos nas suas diferenças. Eles são iguais apenas perante a lei, do ponto de vista da igualdade de direitos. A lei, derivada dessa noção de justiça, regula as relações entre esses indivíduos, diante da qual todos estão obrigados e são responsáveis pelos atos que praticam. O Estado, por conseqüência, deve ser o instrumento para assegurar a liberdade individual, a propriedade privada e a concorrência econômica dos agentes sociais. Nessa condição, o poder estatal deve ser controlado e a sua esfera de ação regulada por leis que regem a sociedade como um todo, visando à paz, à estabilidade da sociedade e à segurança dos negócios particulares. Como é o interesse pessoal que determina o que é melhor para o indivíduo, cada um busca realizar seus fins utilizando o míni-

14 Idem, p. 509. Na Alemanha, além das formulações do liberalismo moral com base em algumas posições de Kant, particularmente quanto à liberdade como autonomia da pessoa, Wilhelm von Humboldt (1767-1835) escreveu em 1792 uma obra que retrata o ideal liberal do Estado, particularmente a liberdade individual. Trata-se do Ensaio sobre os limites da atividade do Estado, onde o autor afirma que "o homem verdadeiramente razoável não pode desejar outro Estado que não aquele no qual cada indivíduo possa gozar da mais ilimitada liberdade de desenvolver a si mesmo, em sua singularidade inconfundível..." Para o liberalismo de Humboldt, o Estado não deve ser um fim em si mesmo, mas apenas um meio para a realização dos fins individuais e para a formação do homem. Um outro representante do liberalismo clássico, J. S. Mill faz um verdadeiro libelo à liberdade individual moderna na sua obra Sobre a liberdade. Afastando-se de uma explicação jusnaturalista da liberdade, Mill fundamenta-a segundo princípios utilitaristas. Pretende interpretar a liberdade como algo que só interessa à pessoa e aos seus fins que lhe são úteis para alcançar a felicidade individual. Para isso, o indivíduo deve ter a liberdade para fazer tudo aquilo que ele deseja sem nenhum impedimento ou força externa. A liberdade, para S. Mill, consiste em procurar o bem de cada um à sua própria maneira. Isso significa definir os limites do poder que a sociedade pode, legitimamente, exercer sobre o indivíduo, a partir do princípio de que "a única parte da conduta por que alguém responde perante a sociedade é a que concerne aos outros. Na parte que diz respeito unicamente a ele próprio, a sua independência é, de direito, absoluta. Sobre si mesmo, sobre o seu próprio corpo e espírito, o indivíduo é soberano". (MILL, S. Sobre a liberdade. Trad. Alberto da Rocha Barros, 2. Ed., Petrópolis, RJ, Vozes, 1991, p. 53).

15 O ensaio "Duas concepções de Liberdade" de Isaiah Berlin distingue esses dois significados de liberdade que se tornaram clássicos na referência à questão da liberdade. 
mo de esforço. A sociedade, ao efetivar o interesse individual dos seus agentes, realiza no conjunto o interesse coletivo.

Qual é a atitude de Hegel diante desse quadro de justificação da política segundo os princípios do individualismo da filosofia política do liberalismo clássico? De início, deve-se destacar que uma das idéias chaves da Filosofia do Direito consiste na exposição do princípio da liberdade individual (Prinzip der subjektiven Freiheit), apresentado como um elemento basilar da modernidade, para a qual a filosofia hegeliana pretende fornecer explicação especulativa com base na Idéia de liberdade. "O direito da particularidade do sujeito de encontrar sua satisfação ou, o que é mesmo, o direito da liberdade subjetiva, constitui o ponto crítico e central na diferença entre o tempo moderno e a antigüidade". ${ }^{16}$ Para Hegel, o grande progresso da modernidade consiste no princípio da autonomia da liberdade individual. O interesse pessoal e o direito particular devem ser respeitados, pois não podem ser determinados de forma heterônoma sem a mediação da vontade livre do indivíduo. Do ponto de vista jurídico e político, esse princípio significa a aceitação dos direitos individuais, o respeito à autonomia no trabalho, o reconhecimento formal da pessoa e da sua explicitação na propriedade privada, elementos estes elaborados pela tradição da filosofia política do Jusnaturalismo moderno, e presentes na filosofia política do liberalismo clássico.

Contudo, na aceitação do princípio da liberdade individual da modernidade, Hegel pretende articular esse princípio com a própria lógica constituidora da própria liberdade. A sua análise tem como ponto de partida a investigação da natureza lógico-conceitual da Idéia de liberdade, isto é, da referência ideal da liberdade como princípio racional que reúne o seu conceito e a sua manifestação empírica, o seu ser-aí. Do ponto de vista conceitual, a apresentação da liberdade como a autoposição de um sujeito que, transitando no seu próprio elemento (na explicitação de si), permanece em si mesmo, circunscreve a própria natureza conceitual da liberdade. Liberdade se define como aquilo que está consigo mesmo, em casa, no seu próprio elemento (bei sich sein): "liberdade consiste justamente em estar consigo mesmo no seu outro, em depender de si, em ser a atividade determinante de si mesmo [...] A liberdade existe apenas lá onde não há para mim nenhum outro que não seja eu mesmo". ${ }^{17}$

A categoria hegeliana do conceito desponta como "aquilo que é livre" num duplo aspecto: totalidade referida a si, unidade que está no seu próprio elemento, "potência substancial que é para ele" - e nessa acepção o conceito é livre porque está em si mesmo - mas, também, como uma totalidade que registra um liberar-se de si mesmo. Nesse sentido, o conceito se institui como autoliberação na infinita diferenciação de si. No seu progredir (no processo de expansão ou ex-posição de si mesmo) ele se libera de si e se explicita num conteúdo. A unidade de si (forma)

${ }^{16}$ HEGEL, G. W. F., Grundlinien der Philosophie des Rechts. Werke 7, Frankfurt am Main: Suhrkamp, 1986, § 124, obs., cf, também: § 185 obs, § 273 ad., § 206 obs.

17 HEGEL, Enzyklopädie der philosophischen Wissenschafte I, Werke 8, Frankfurt am Main: Suhrkamp, 1986, § 24, ad. 
com a difusão de si (conteúdo) na permanência a si mesmo é o que caracteriza o conceito como liberdade (Freiheit) nesse duplo sentido: auto-referência (bei sich) e liberação (Befreien).

A ação moral, o direito, a política e o Estado são manifestações objetivas dessa liberdade autárquica do conceito, ou seja, determinações conceituais através das quais o conceito se desdobra no seu ser-aí (Dasein) como Idéia (de liberdade). Desta forma, a auto-referencialidade da liberdade exige um princípio adequado a ela mesma, isto é, ela deve ser apreendida segundo um fundamento conceitual que não pode ser deduzido de um direito natural e nem se reduz ao aspecto de um simples dever-ser formal.

Tendo por base a compreensão da liberdade do ponto de vista lógicoconceitual, os temas básicos da doutrina liberal (direito de propriedade, consenso contratual, individualismo, liberdade econômica, etc.) são criticamente recepcionados por Hegel. Esta posição crítica consiste, basicamente, em rejeitar na concepção individualista dos modernos o seu caráter abstrato que concebe o indivíduo como realidade primeira, auto-referente. Imaginar o indivíduo como fim e princípio do Estado significa operar com as categorias do direito privado (contratualismo) e com os princípios éticos dos benefícios pessoais (utilitarismo), tanto um como outro são válidos nas relações pessoais e intersubjetivas da sociedade civil, onde encontram sua justificativa e limites. No que se refere ao Estado, o princípio regulador "não é em absoluto um contrato, e nem sua essência substancial é, de um modo incondicionado, a proteção e a segurança da vida e da propriedade dos indivíduos singulares". ${ }^{18}$ Contudo, o espaço da liberdade individual anunciada pelo liberalismo é preservado na esfera de relações sociais e econômicas, marcadas pelos interesses individuais da sociedade civil-burguesa (bürgerliche Gesellschaft). Nela, as instituições civis têm o dever de proteger os seus membros, dando-lhes a devida segurança nos negócios privados de acordo com a liberdade de cada um.

Desse ponto de vista, Hegel compartilha o ideal liberal no acolhimento do postulado da autonomia da sociedade civil na sua capacidade de autosubsistência, na criação de espaços que ela constitui para o exercício da liberdade dos indivíduos, na livre administração dos negócios privados, e na promoção do bem-estar dos sujeitos. Mas, este espaço privado do "estado da necessidade e do entendimento" não deve representar o fim último da sociabilidade humana e, por conseguinte, atribuir ao Estado um caráter negativo, um mal necessário ou mero instrumento para a realização dos interesses privados do indivíduo burguês em detrimento do citoyen, desprezando, assim, a possibilidade de realização ulterior dessa sociabilidade.

A aceitação da liberdade no seu fundamento auto-referencial que se revela no Estado e pelo Estado, não leva à negação da liberdade individual. Pelo contrário, ela é um aspecto essencial na estrutura da Filosofia do Direito. Esta obra, organi-

18 HEGEL, Grundlinien der Philosophie des Rechts, op. cit., § 100, obs. 
zada segundo a determinação lógica da Idéia de liberdade, pela qual as formas superiores da vida ética da sociedade civil e do Estado fundamentam a liberdade individual, começa pela afirmação da liberdade da pessoa (Direito Abstrato) e da liberdade subjetiva (Moralidade) como momentos abstratos e formais da liberdade individual, e termina pela sua realização efetiva na eticidade (Sittlichkeit) nas esferas comunitárias da Família, da Sociedade Civil burguesa e na figura da sua efetividade, o Estado.

As relações do hegelianismo político com os princípios liberais, a partir do reconhecimento da liberdade subjetiva como elemento essencial na filosofia política de ambos, tornam-se mais complexas, e adquirem uma melhor avaliação, se analisadas na perspectiva do projeto conciliador de Hegel entre os ideais da totalidade política da pólis com o princípio da liberdade individual da modernidade. Nesse sentido, a intenção do filósofo se distancia do liberalismo, pois consiste na recepção crítica (especulativa) do princípio liberal da liberdade subjetiva, já presente no Jusnaturalismo moderno, à luz da incorporação, também crítica, da tradição do organicismo da filosofia política clássica. Por outras palavras, o individualismo dos modernos é criticado e, no entanto, a liberdade individual permanece e se articula dialeticamente com a noção de auto-referencialidade da lógica hegeliana, a qual se desdobra na concepção organicismo político presente na Filosofia do Direito. ${ }^{19}$

Se, de um lado, Estado hegeliano não pode ser visto como a elaboração teórica do prussianismo, e de que a Filosofia do Direito esconde, debaixo da ardilosa argumentação dialética, os princípios do Estado autoritário; por outro lado, é preciso mostrar em que medida e como o filósofo recepciona criticamente o elemento da liberdade individual, e afasta-se dos pressupostos da filosofia do liberalismo. A questão permanece: se o hegelianismo se move no universo da lógica autoreferente da Idéia de liberdade e recusa a referência do indivíduo como mônada auto-suficiente, sua filosofia política é compatível e conciliável com o tema da liberdade do indivíduo, a qual parece resistir às tentativas, mesmo que teóricas, de conciliação com qualquer forma de holismo? Como é possível a afirmação do princípio da liberdade do indivíduo sem recorrer aos cânones da doutrina liberal, fora dos quais esse princípio parece não encontrar solo de sustentação? Enfim, se o liberalismo afirma a primazia dos direitos do indivíduo, podem eles subsistir no seio da crítica hegeliana ao individualismo? A intenção conciliatória de Hegel (entre a liberdade individual dos modernos e o sentido ético-político da comunidade dos gregos) orienta a sua filosofia política numa perspectiva que o afasta dos princípios do liberalismo clássico, bem como do conservadorismo estatizante.

Apesar de acatar o princípio da autonomia do indivíduo, Hegel não é um teórico do Estado liberal. Percebe que este princípio é insuficiente para a fundamentação do Estado moderno, sem o qual os direitos individuais não teriam nenhuma

19 Na fórmula de Ilting: "trata-se então, segundo Hegel, de realizar sob as condições dos tempos modernos esta idéia da liberdade que reúne não só o sentido de comunidade dos antigos, mas também a idéia moderna de indivíduo autônomo" (ILTING, K-H. La forme logique et systématique de la Philosophie du Droit. In: Hegel et la Philosophie du Droit. Paris: PUF, 1979, p. 58). 
garantia para o seu exercício e nenhuma base para a sua postulação. Essa perspectiva conduz necessariamente ao estatuto da filosofia hegeliana face ao princípio da liberdade individual que o liberalismo clássico propugnou, tomando-o como bandeira política e verdadeiro cânone filosófico, o qual se explicita na idéia de que os indivíduos, agentes conscientes, constituem a realidade social primeira e o fim último do Estado.

Se a interpretação "liberal" de Hegel visa, com razão, afastar o filósofo do rótulo de pensador autoritário ou mesmo conservador, estaríamos, com isso, autorizados a concluir que Hegel é um filosofo liberal? Um equívoco bastante comum que surge na comparação de Hegel com os liberais consiste em colocar a relação de forma disjuntiva: ou a liberdade do indivíduo, por si só, é o elemento principal de uma teoria política necessariamente liberal - e a doutrina hegeliana é condenada como uma forma de autoritarismo que nega esta liberdade - ou sacrificamos a liberdade individual em favor do Estado e, nesse caso, a filosofia política de Hegel é antiliberal.

\section{A leitura rawlsiana do liberalismo de Hegel}

A intenção rawlsiana de avaliação crítica do hegelianismo, enquanto liberalismo da liberdade, pode ser evidenciada nos seguintes aspectos, os quais sugerem, também, uma tentativa de resposta às críticas comunitaristas:

a) O exame do § 260 da Filosofia do Direito de Hegel.

Com o objetivo de tornar plausível a noção hegeliana de Estado numa perspectiva nitidamente liberal, Rawls comenta o § 260 da Filosofia do Direito de Hegel, considerado pelo filósofo americano como uma importante passagem, dividindo-o em partes. ${ }^{20}$ Em cada uma delas, procura apresentar uma interpretação compatível com o liberalismo político, segundo a visão contratualista do Estado, afastando-se do substancialismo hegeliano.

Na primeira parte (a), a afirmação de que "o Estado é a realidade efetiva da liberdade concreta", Rawls entende essa liberdade como aquilo que "possibilita aos

\footnotetext{
O § 260 inicia a análise do "Direito público interno" tematizando a realização efetiva do indivíduo e da sua liberdade no Estado. É dividido por Rawls em 4 partes: [a] "O Estado é a realidade efetiva da liberdade concreta; mas a liberdade concreta consiste em que a singularidade pessoal e os seus interesses particulares tanto tenham o seu desenvolvimento completo e o reconhecimento do seu direito para si (no sistema da família e da sociedade civil-burguesa), quanto, [b] em parte passem por si mesmos ao interesse do universal, em parte reconheçam-no, com saber e vontade, como o seu espírito substancial, e sejam ativos a favor do universal como seu fim-último, [c] e isso de tal maneira que nem o universal valha e possa ser consumado sem o interesse, o saber e o querer particulares, nem os indivíduos vivam apenas para estes como pessoas privadas, sem querê-los, simultaneamente, no universal e para o universal e sem que tenham uma atividade eficaz consciente desse fim. [d] O princípio dos Estados modernos tem este vigor e esta profundidade prodigiosos de deixar o princípio da subjetividade plenificar-se até o extremo autônomo da particularidade pessoal e, ao mesmo tempo, de reconduzi-lo à unidade substancial, e, assim, de manter essa unidade substancial nesse princípio da subjetividade." (Filosofia do Direito, trad. Marcos L. Muller, In: Textos Didáticos, Campinas: IFCH/UNICAMP, 1998, § 260.)
} 
indivíduos realizarem seus interesses particulares quando esses interesses forem desenvolvidos dentro dos limites permitidos pelos direitos e deveres especificados na família e na sociedade civil e protegidos pelo governo da lei" ${ }^{21} \mathrm{Na}$ segunda parte (b), interpreta a noção hegeliana de integração do indivíduo no 'interesse do universal', nele encontrando o seu 'espírito substancial' e o seu 'fim-último', tornando-se cidadão em oposição ao 'Bürger', a partir da sua teoria, isto é, o fato de que a "sociedade é mantida junto não simplesmente para a satisfação de interesses particulares, mas por um senso de ordem racional, e que ela é regulada por, vamos dizer, uma concepção comum de justiça que reconhece os méritos e as reivindicações de todos os setores da sociedade. O que eleva a vida humana acima do usual mundo burguês (bürgerliche) é o reconhecimento do interesse universal de todos os cidadãos em participar e manter o sistema total das instituições sociais e políticas do estado moderno que torna possível as suas liberdades."22 Para Rawls, o objetivo do projeto conciliador de Hegel, entre o indivíduo, a sua liberdade e a substância superior do Estado, consiste na integração dos sujeitos no universal (coletivo), nele reconhecendo os seus próprios interesses e suas finalidades últimas. Na terceira parte (c) do § 260, o interesse universal só alcança a sua realização com o conhecimento e a aceitação dos indivíduos na sociedade civil. Na ótica rawlsiana, os indivíduos não vivem apenas para os seus interesses particulares como pessoas privadas. Orientam-se, também, para um fim superior, ou seja, por uma "concepção de justiça como um bem-comum" ${ }^{23}$ Na última parte (d) do § 260, Rawls diz que a moderna constituição, na teoria hegeliana, ao permitir a liberdade na sociedade civil, concede enorme força ao Estado, desde que o interesse universal dos cidadãos seja reconhecido.

Um ponto comum na interpretação rawlsiana ao § 260 é a menção, nas quatro partes do parágrafo, à sociedade civil cuja importância e necessidade para os cidadãos e para as liberdades individuais só é possível, do ponto de vista hegeliano, pelo reconhecimento do interesse universal dos indivíduos, ou de um fim superior que permite a própria sobrevivência desta sociedade. A perspectiva da superação dos interesses particulares da sociedade civil na universalidade do Estado é assumida na linha do liberalismo político sob a ótica de que o Estado é uma necessidade enquanto expressão de uma "concepção comum de justiça", o elemento de "ordem racional" que regula todos os setores da sociedade civil.

a) O direito abstrato hegeliano e concepção de pessoa na posição original de Rawls.

A evolução do pensamento de Rawls, no sentido de elaborar uma concepção política de pessoa, reforçou aquilo que sempre esteve presente na sua teoria: a idéia de que é preciso constituir um sujeito (político) necessariamente formal, um ser racional indiferente ao conteúdo real da condição humana a fim de que o indi-

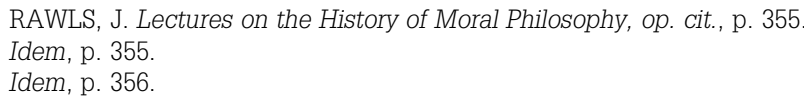


víduo na "posição original", através dos seus representantes, possa escolher princípios de justiça a partir da concepção da autonomia racional. Os aspectos físicos, antropológicos, sociais, biológicos dos indivíduos que habitam uma determinada sociedade devem ser abstraídos, restando apenas a categoria formal da pessoa (e das faculdades morais a ela inerentes), metamorfoseando-a numa espécie de "eu transcendental" político.

Tal procedimento remete ao constructo hegeliano do Direito Abstrato na primeira parte da Filosofia do Direito, a qual trata de assuntos ligados à tradição do Jusnaturalismo moderno, como a propriedade, o contrato, a justiça, a violência, etc. O ponto de partida é o indivíduo, considerado como pessoa na abstração das suas relações com os outros homens e com as coisas da natureza, momento imediato no desenvolvimento da Idéia de liberdade. A noção de indivíduo é pensada no quadro da Filosofia do Direito de Hegel como individualidade posta na determinação elementar e imediata do direito (abstrato), pela qual ele desponta antes de qualquer outra determinação. O desenvolvimento da Idéia de liberdade apresentase, no processo do seu desenvolvimento, o momento da imediatidade na figura da pessoa (Person) do direito abstrato, no qual "a vontade em si singular de um sujeito" ${ }^{24}$ encontra-se numa relação abstrata consigo mesma, como identidade abstrata da personalidade (Personlichkeit), isto é, a capacidade de direito (pessoa).

Com o recurso lógico à imediatidade, Hegel não apenas "personaliza" a liberdade na figura da pessoa - onde a particularidade, embora abstraída, não está excluída - como também elimina seu fundamento natural. Na noção de pessoa, as diferenças, enquanto expressões de desejos que se exteriorizam, têm a garantia peremptória de sua manifestação, a partir da universalidade ou do conceito identitário do direito (subjetivo) da pessoa, também presente na figura do indivíduo proprietário - "a liberdade de uma pessoa individual que se relaciona apenas consigo mesma"25 -, nos indivíduos sujeitos de relações contratuais, e naqueles que podem violar pela injustiça e pelo delito o direito das outras pessoas.

De qualquer modo, a necessidade do momento da igualdade formal, presente na universalidade abstrata da pessoa, constitui o ponto de partida, abstrato mas necessário, no desenvolvimento da Idéia de liberdade. Esta se enriquece no processo de determinação superior do sujeito moral da Moralität, alcançando a sua efetividade concreta na esfera superior da Sittlichkeit. Hegel diz que o "conceito de liberdade, existindo sem outra determinação ou desenvolvimento, é a subjetividade abstrata enquanto pessoa apta a possuir apenas esta determinidade abstrata da personalidade, constitui a verdadeira igualdade dos homens". ${ }^{26}$

O abstracionismo rawlsiano da posição original, bem como a noção de pessoa que é proposta nesse momento, embora sendo de outra ordem e visando outros objetivos, guarda uma certa similaridade com o recurso hegeliano do Direito Abs-

HEGEL. Philosophie des Rechts, op. cit., § 34.

Idem, § 40.

HEGEL, G. W. F. Enzyklopädie der Philosophischen Wissenschaften im Grundrisse. Herausgegeben von F. Nicolin e O. Pöggeler, Hamburg: Felix Meiner, 1969, § 539. 
trato, no sentido da postulação da identidade igualitária do formalismo da pessoa, possível por um processo de abstração. Com efeito, Rawls distingue um sistema de instituições sociais e políticas, entendido como uma estrutura abstrata que pode ser descrito por certos princípios e preceitos, por seus vários poderes e agências e, por outro lado, como as "formas de vida vividas e animadas pelo povo no mundo." Observa que o sistema do direito, particularmente a propriedade, não pode ser justificado em virtude dele preencher as necessidades ou desejos das pessoas, objetivando o seu bem-estar. De modo análogo, Hegel exclui o ponto de vista utilitarista para a justificação da propriedade. O seu fundamento decorre apenas do fato dela constituir o ser-aí da liberdade, e a sua razão de ser não se deve à utilidade, ou às vantagens que ela possa oferecer aos indivíduos proprietários ou à sociedade como um todo. Nesse sentido, Hegel junto com Kant, são considerados filósofos "radicalmente opostos ao utilitarismo" na justificação do sistema do direito, e que isso é "característico de um liberalismo da liberdade,"27 conclui Rawls.

A despeito de possíveis semelhanças, diferenças devem ser ressaltadas entre o procedimento hegeliano e rawlsinano no uso e na caracterização do ponto de partida abstrato. Uma delas consiste em avaliar o estatuto da pessoa na sua formulação abstrata. Para Hegel, o momento do direito consiste em assegurar a categoria jurídica do respeito à pessoa, isto é, acatar o direito formal do outro indivíduo de ser igualmente livre, de ter a prerrogativa jurídica desse direito, de agir como tal e de ser reconhecido por outrem como possuidor da essência universal da liberdade. Tal capacidade de direito é destituída dos atributos morais, determinações de uma segunda esfera (esta ainda abstrata se comparada com a realidade efetiva da eticidade), que surgem como necessidade para o enriquecimento moral do vazio formal da pessoa jurídica. Para Rawls, a pessoa na sua abstração possui, ainda assim, dois poderes morais inerentes à sua personalidade: a capacidade (ser razoável) de ter "um efetivo senso de justiça" e de respeitar os termos eqüitativos da cooperação, e a capacidade de ter e de perseguir "uma particular concepção de bem", como algo que é racional. "De modo mais preciso, ser capaz de um senso de justiça é ser capaz de compreender, de aplicar e normalmente de ser movido por um desejo eficaz de agir a partir de princípios de justiça (e não simplesmente de acordo com eles) na condição de termos eqüitativos de cooperação social. Ser capaz de uma concepção do bem é ser capaz de formar, de revisar e de buscar racionalmente uma concepção assim, isto é, uma concepção do que é, para nós, uma vida humana que merece ser vivida." 28

Uma outra diferença consiste em determinar os objetivos do abstracionismo. Se o ponto de partida da Filosofia do Direito é a afirmação do direito (subjetivo) do indivíduo segundo a tradição do Jusnaturalismo moderno, este ponto de partida (abstrato) é necessário mas insuficiente, pois o conceito hegeliano de Sittlichkeit deve prevalecer como esfera de superação (e, também, de manutenção) do indivi-

27 RAWLS, J. Lectures on the History of Moral Philosophy, op. cit., p. 343.

${ }^{28}$ RAWLS, J. Justiça e Democracia, op. cit., p. 158. 
dualismo dos modernos, centrado na noção de liberdade individual. Isso significa dizer que o pressuposto abstrato só adquire o seu estatuto quando encontra o seu fundamento (as formas superiores da vida social baseadas na idéia do pertencimento social e político da comunidade) que repõe ou assegura esse pressuposto. Para Hegel, a liberdade individual é insuficiente na sua formulação jurídica abstrata, se não for superada (e, ao mesmo tempo, conservada) em instâncias da efetividade da comunidade política. A abstração para Hegel significa a ausência de determinidades próprias do início - "absoluta indiferença ou identidade" - que demonstra ser estruturalmente (logicamente) insuficiente na sua imediatidade, razão pela qual ele precisa ser superado (e, também, mantido) em direção às determinações mais ricas que permitem a sua realização efetiva.

Para Rawls, o acordo ou o contrato na "posição original" deve ser entendido de forma hipotética e não histórica, e a estratégia para a sua construção é o recurso ao chamado "véu de ignorância". Ele é pensado de forma hipotética porque é o "resultado de um processo racional de deliberação nas condições ideais e não históricas." ${ }^{29} \mathrm{O}$ abstracionismo da "posição original" passa a ser "um procedimento de representação ou um experimento mental" para formalizar a condição inicial (igualdade formal) de representantes dos cidadãos, a partir da qual eles chegam a um acordo sobre os termos justos da cooperação social, os quais podem ser enunciados sob a forma de princípios de justiça. O que leva os indivíduos à posição original é a necessidade desse acordo derivado dos próprios sujeitos, a partir de uma situação considerada eqüitativa para todos, donde a necessidade da abstração, a qual é tomada a partir da sugestão do seu sentido etimológico (do latim abstrahere), significando considerar isoladamente, separar, apartar A abstração significa, então, um recurso metodológico de despojamento das características da vida social que podem interferir no acordo eqüitativo entre pessoas que devem ser iguais e livres. Daí a necessidade do "véu de ignorância" que obscurece o que as pessoas realmente são, delas separando as características e circunstâncias particulares que as identificam, tornado-as simétricas naquilo que lhes é essencial.

Apesar das diferenças no uso metodológico do abstracionismo, tanto Hegel como Rawls constroem um princípio normativo de pessoa que permite pensá-la segundo um referencial histórico e institucional da nossa vida social e política, no qual esse princípio adquire consistência material. Para o primeiro, o formalismo da pessoa é um momento lógico que o individualismo (liberal) da modernidade retrata como uma necessidade histórica, mas que atesta, ao mesmo tempo, uma insuficiência radical demonstrada pelo seu abstracionismo. Para o segundo, o formalismo é uma construção necessária para assegurar a validade histórica da democracia liberal, que pode ser exprimida por princípios de justiça, os mais apropriados para a estrutura básica da sociedade.

${ }^{29}$ Idem, p. 23. 
b) A "comunidade" rawlsiana e a Sittlichkeit hegeliana

Rawls defende uma concepção de comunidade que se diferencia daquela proposta pelo hobbesiano com ênfase no atomismo social, bem como a do liberalismo clássico (Locke e A. Smith, por ex.), que vê a comunidade como a extensão coletiva dos interesses privados de ordem econômica. A "comunidade" rawlsiana deriva da união social das atividades cooperativas que os homens estabelecem quando compartilham fins e participam de um empreendimento comum, para além do simples valor utilitário da economia.

O princípio "estruturante fundamental" é o da "sociedade como um sistema eqüitativo de cooperação social entre pessoas livres e iguais encaradas como membros plenamente cooperantes da sociedade ao longo da vida inteira" ${ }^{30}$ A essa idéia, assumida como implícita na cultura pública de uma sociedade democrática, estão associadas outras básicas: de uma sociedade bem-ordenada, da estrutura básica de tal sociedade, da concepção política de pessoa como livre e igual, de posição original e a idéia de justificação pública.

A idéia de cooperação é, por conseguinte, de grande importância para o liberalismo político de Rawls. Ela se apresenta como uma "idéia intuitiva fundamental" implícita na cultura pública de uma sociedade democrática, por si plural e refratária ao espírito de identidade comunitária. Os indivíduos agem movidos pela escolha de caminhos mais razoáveis, que consiste em perguntar quais são os "termos justos da cooperação social" entre os cidadãos que se caracterizam como seres livres e iguais, e que podem ser cooperativos a partir de regras publicamente reconhecidas e justas. A noção de cooperação social que Rawls emprega não se reduz à idéia de uma atividade coordenada segundo princípios da eficaz organização social, mas possui o elemento do benefício mútuo para a concretização dos fins essenciais da vida humana, envolvendo as idéias de reciprocidade e de mutualidade presentes da noção do razoável, sem que isso possa representar um ideal de sociabilidade comunitária. O elemento do racional refere-se à vantagem que os participantes obtém no empreendimento cooperativo, diferente daqueles que norteiam as parcerias e associações dos grupos privados que atuam na sociedade.

Uma sociedade estável e bem-ordenada deve estar fundada em laços sociais de união, ausentes em associações baseadas no frágil modelo do simples "modus vivendi" dos interesses privados econômicos ou sociais; mas, nem por isso, deve produzir uma forma de sociabilidade comunitária, cujos membros estariam vinculados em torno de uma idéia de bem para a realização de certos valores e objetivos comuns. Os vínculos comunitários não podem ser deduzidos de concepções religiosas ou morais que decidem qual bem é o melhor para a vida.

O caráter da cooperação social só é possível, para Hegel, no pressuposto de uma sociabilidade política inscrita na realidade efetiva da cidadania nas instituições políticas do Estado, e na perspectiva não liberal do ideal comunitário aristo-

RAWLS, J. O liberalismo Político. Trad. João S. Nunes, Lisboa: Ed. Presença, 1997 p. 38. 
télico do homem como zoon politikon. Para Rawls, a teoria da justiça como eqüidade, ao não se fundamentar numa doutrina exaustiva moral, religiosa ou filosófi$\mathrm{ca}$, abandona este ideal de comunidade política. A unidade da sociedade deve resultar de um consenso por justaposição em torno de uma concepção política de justiça, pois o que os homens compartilham é uma concepção comum de justiça.

Ao propor uma noção "comunitária" de cooperação social, Rawls entende que a crítica à sua teoria é improcedente, pelo fato de não considerar o enraizamento do povo nas organizações sociais e políticas. O argumento da sociabilidade é deduzido da idéia de que a liberdade e a igualdade das pessoas morais devem ter uma forma pública. Nessa medida, a teoria da justiça como eqüidade leva em conta a natureza social do homem, e, sem abrir mão de uma concepção moral de base individualista, pois advoga uma relação eqüitativa de pessoas iguais e livres na posição original, concebe valores sociais que não sacrificam a liberdade e a integridade da pessoa.

A perspectiva da Sittlichkeit hegeliana dispensa o elemento rawlsiano da cooperação com características de natureza social, mas aderente ao elemento individualista da pessoa, no qual é dado o atributo coextensivo da sociabilidade cooperativa. Ou seja, a concepção da pessoa encontra-se em conjunção com a idéia associada da cooperação social. Esta correlação é significativa na perspectiva liberal de Rawls, no sentido de introduzir na concepção de pessoa a idéia da cooperação social, evitando, assim, a pecha de atomismo societário sem abandonar a perspectiva do individualismo liberal.

d) O substancialismo hegeliano e o contratualismo rawlsiano

No século XIX, Hegel abandona a tradição do contratualismo da escola do Jusnaturalismo moderno (de Hobbes a Kant), retomando a antiga perspectiva da filosofia política de compreensão do Estado como totalidade (orgânica) ética. Rawls, no final do século XX, retoma essa tradição, procurando uma alternativa não utilitarista para uma teoria da justiça, de fundamental importância para legitimar as sociedades e o Estados liberais modernos.

Hegel chamou atenção para a confusão, presente nas teorias contratualistas do seu tempo, entre a sociedade civil-burguesa - regida pelos princípios do contrato do direito privado, e subordinada à lógica da associação contingente de pessoas voltadas para os interesses particulares - e o Estado. Enquanto "substância espiritual," este rege-se pelo princípio da universalidade e da necessidade do direito público que transcende a particularidade, e independe dos interesses privados e contingentes da vontade associativa e contratual dos indivíduos. A noção de contrato social, para Hegel, acaba operando uma transposição indevida da forma de constituição e funcionamento da sociedade civil-burguesa (à qual o contratualismo deve se limitar) para o Estado. Além disso, o filósofo chama a atenção para um segundo equívoco: o modelo contratualista só é possível na desconsideração da constituição histórica eminentemente espiritual (social/política) do homem, atribuindo ao ser humano determinadas qualidades naturais (a liberdade, por exemplo) derivadas de um hipotético estado de natureza. 
Rawls recusa o substancialismo hegeliano, pelo qual o Estado, momento superior da comunidade ética, "é um organismo, isto é, o desenvolvimento da Idéia em suas diferenças." Em oposição a essa concepção, o liberalismo político procura dar uma feição kantiana à teoria contratualista que deve ser compatível com a constituição de uma esfera pública. ${ }^{31}$ Ao comentar o adendo ao § 156 da Filosofia do Direito, ${ }^{32}$ onde Hegel afirma que há só duas alternativas possíveis para compreender a realidade do Estado e a força constituinte das instituições políticas - o atomismo, que ele rejeita, ou alternativa verdadeira por ele proposta, do substancialismo como unidade do universal e do individual -, Rawls pensa uma terceira via, sugerida pela interpretação kantiana do contrato social originário.

Essa interpretação, assumida por Rawls, livra-o da alternativa proposta por Hegel: ou o atomismo (presente na versão do contratualismo de Hobbes e de Locke) que tem como ponto de partida indivíduos independentes dos laços sociais; ou o substancialismo da idéia de Estado, no qual os indivíduos encontramse organicamente vinculados. Segundo Rawls, há duas características cruciais nessa interpretação. A primeira é a especial natureza deste contrato: ele "é a união de muitos indivíduos - de todos os indivíduos - para um bem comum por todos compartilhado." ${ }^{33} \mathrm{O}$ estado de natureza deve ser abandonado e a totalidade dos indivíduos deve se submeter a uma lei pública, pois, o "Estado é uma união de pessoas sob princípios do direito público." ${ }^{34}$ A segunda característica do contrato social kantiano está na sua compreensão como uma idéia de razão e, como tal, ele é o critério regulador para a constituição e para as leis básicas.

A via proposta por Kant pensa o contrato social como: "(1) um acordo hipotético entre todos os membros de uma sociedade e não somente entre alguns deles, (2) enquanto membros da sociedade (enquanto cidadãos) e não enquanto indivíduos que ocupam uma posição ou um papel particular no seio da sociedade. Na versão kantiana dessa doutrina, a que chamo teoria da justiça como eqüidade, (3) os parceiros são considerados e se consideram eles próprios como pessoas morais livres e iguais; e (4) o conteúdo do acordo trata dos princípios primeiros que vão governar a estrutura básica." ${ }^{35}$

Para reforçar essa interpretação, Rawls se distancia da teoria do liberalismo libertário, para o qual o Estado é "equivalente a qualquer outra associação privada.

${ }^{31}$ A filosofia política de Kant, no resumo que o próprio Rawls apresenta, possui as seguintes idéias principais: o essencial papel político da razão pública livre; a idéia do contrato social ou original; a idéia dos cidadãos como membros co-legisladores do estado; a rejeição do princípio de felicidade como critério das leis públicas de base; a liberdade de religião e o direito de perseguir nossa felicidade segundo o nosso próprio modo livre da interferência do estado, contanto que respeitemos os direitos dos outros. (cf., Lectures on the History of Moral Philosophy, op. cit., p. 362-363)

32 Diz o adendo: "Em relação ao ético (Sittlichen) apenas dois pontos de vista são, então, possíveis: ou se parte da substancialidade ou se procede atomisticamente, elevando-se da particularidade como fundamento. Este último ponto de vista é destituído de Espírito, porque ele conduz apenas a uma justaposição, pois o Espírito não é algo individual, mas a unidade do individual e do universal." (HEGEL. Philosophie des Rechts, op. cit., § 165, ad.)

33 RAWLS, J. Lectures on the History of Moral Philosophy, op. cit., p. 363.

4 Idem, p. 363.

5 RAWLS, J. Justiça e Democracia, op. cit., p. 4-. 
Ele nasce da mesma maneira que outras associações, e sua formação [...] se rege pelos mesmos princípios." ${ }^{36}$ A posição de Rawls é a de que "embora a concepção libertária faça grande uso da noção de acordo, ela não é em absoluto uma teoria do contrato social, pois uma teoria do contrato social encara o pacto original como o estabelecimento de um sistema de leis públicas comuns que define e regula a autoridade política e se aplica a cada um enquanto cidadão. A autoridade política e a cidadania devem ser compreendidas por meio da concepção do próprio contrato social. Concebendo o Estado como uma associação privada, a doutrina libertária rejeita as idéias fundamentais da teoria do contrato." ${ }^{37}$

É na "posição original" que se recorre à idéia do contrato social que estabelece princípios (de justiça), de inspiração kantiana, e cujo objeto é a "estrutura básica da sociedade." "Se essa estrutura não for convenientemente regulada e ajustada, o processo social deixará de ser justo, por mais justas e eqüitativas que possam parecer as transações particulares consideradas separadamente. ${ }^{\prime 38}$ Isso significa que as instituições que fazem parte da estrutura básica da sociedade devem servir de fundamento das demais ações contratuais privadas que serão levadas a cabo na sociedade, as quais terão por parâmetro os princípios de justiça.

e) A sociedade liberal não possui fins universais e coletivos e o menosprezo do liberalismo à dimensão pública.

A crítica de inspiração hegeliana de que a sociedade existe apenas para servir aos objetivos particulares e privados dos seus membros, permanecendo na lógica da sociedade civil (o mesmo valendo para a vida pública do Estado), aplica-se, segundo Rawls, mais ao modelo hobbesiano, o qual Hegel tem em mente na crítica àquelas teorias que instrumentalizam o Estado aos interesses privados da sociedade civil. De fato, numa sociedade assim compreendida não pode haver fins universais superiores publicamente compartilhados. Mas isso não é verdadeiro para o liberalismo de Kant, de J.S. Mill, como também para o de Rawls. Este último nega a interpretação de que os dois princípios de justiça devem ser pensados isoladamente, referidos apenas às ações individuais dos sujeitos, uma vez que eles se aplicam à estrutura básica da sociedade.

Portanto, "é incorreto dizer que num liberalismo da liberdade o Estado não tem fins publicamente compartilhados [...]." ${ }^{39}$ Mesmo porque, observa Rawls, a tradição liberal não omite a importância do espaço público na vida política, na qual os interesses privados e os fins particulares são qualificados no contexto da universalidade do interesse público que esse espaço viabiliza. O que se nega é a idéia de que o maior bem dos seres humanos seja realizado na forma da sua constituição política comum, na esteira do ideal da vida pública da cidadania na polis grega. Outros "grandes valores coletivos, como os da ciência, arte e cultura, ou

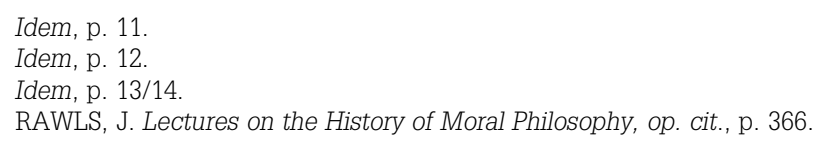


aqueles da vida privada e pessoal, como os da afeição, da amizade e do amor" ${ }^{m 0}$ podem ser evocados, podendo adquirir uma dimensão pública.

De que forma se dá a representação dos bens políticos (públicos) que interessam ao povo e ao Estado como um todo? É sabido que, para Hegel, o povo deve ser pensado nas suas instâncias de organização, de tal modo que a representação política é feita por estamentos, corporações e associações às quais os indivíduos organicamente pertencem em suas ocupações profissionais na sociedade civilburguesa. Os indivíduos, através do seus representantes, participam da vida política, não enquanto vontades isoladas, mas como membros de entidades coletivas. Só assim os interesses podem, de uma forma mais racional, ser defendidos e representados junto ao Estado.

Rawls observa que essa forma de representação política não é mais possível no esquema liberal do voto personalizado: "Hegel rejeita a idéia de "uma pessoa, um voto', sob o fundamento que ela expressa a idéia democrática e individualista de que cada pessoa, como um unidade atomística, tem o direito básico de participar igualmente na deliberação política" ${ }^{\prime 41}$ Entende as razões de Hegel em adotar esse procedimento, principalmente a necessidade de refrear as influências econômicas sobre o processo político que deve ter um sentido público na elaboração da lei. Contudo, a sugestão constitucional hegeliana dos três estados está fora de uso e nos ensina muito pouco, observa Rawls.

\section{Conclusão}

O estudo de alguns aspectos importantes do hegelianismo político empreendidos por Rawls estimula uma apreciação mais adequada das teses do liberalismo político. A inclusão de Hegel na linha do liberalismo da liberdade e, mais, a atribuição à Filosofia do Direito como inspiradora de uma das funções da filosofia política - a da reconciliação - atesta a importância de Hegel na investigação dos temas básicos de uma teoria política. Essa importância torna-se ainda mais visível, e nada desprezível, se o filósofo alemão for considerado uma das fontes da chamada crítica comunitarista.

A filosofia hegeliana, ao tematizar a época moderna marcada pelo subjetivismo que se desdobra num individualismo exacerbado e monadológico, pretende integrar a liberdade individual numa instância ética (social e política), seu fundamento e solo de expressão. Contudo, a universalidade do Estado hegeliano não pode ser pensada sem a necessária dimensão da particularidade da liberdade do indivíduo. Esta integração conciliadora não nega a liberdade individual, antes representa a sua afirmação a partir de uma medida que lhe "com-preende," mas não se reduz ao metro da liberdade auto-referente do individuo.

Hegel não despreza a liberdade individual, podendo ser classificado como um dos teóricos da chamado liberalismo da liberdade, e, apesar da presença de alguns

Idem, p. 369.

Idem, p. 356. 
aspectos liberais na sua filosofia política - afinal, a instância da esfera privada voltada para a liberdade dos indivíduos e organizada segundo os princípios econômicos da livre concorrência exige um sistema social e regras jurídicas opostas ao domínio do Estado. No movimento de Aufhebung dessa liberdade individual, a noção hegeliana do poder político orgânico, integrador e conciliador tem prevalência sobre a concepção minimalista de poder da filosofia liberal que se assenta sobre a juridicidade das liberdades individuais. O Estado hegeliano se apresenta como instância necessária, não só para a solução dos conflitos, como também a razão de ser da própria liberdade subjetiva. O seu caráter integrador ético-político em relação à desagregação liberalizante do individualismo social se constitui em elemento que assegura a constante reposição da sociedade civil burguesa dentro da lógica liberal do seu funcionamento, evitando, assim, o seu processo de autodissolução. O liberalismo por si só, enquanto doutrina impermeável a qualquer crítica e correção especulativa, permanece atomista ${ }^{42}$ e, de certa forma, preso a um abstracionismo idealista, na medida em que a liberdade individual e os direitos do homem assumem uma espécie de medida transcendental que determina idealmente a sociabilidade política dos indivíduos.

Rawls entende a função reconciliadora da filosofia, atribuída a Hegel, no sentido de conferir à filosofia política o papel de "tentar acalmar nossa raiva e nossa frustração contra a sociedade e sua história mostrando-nos como suas instituições, quando propriamente entendidas de um ponto de vista filosófico, são racionais, e se desenvolveram ao longo do tempo da maneira como o fizeram para atingir sua forma racional atual." ${ }^{43}$ Se essa forma racional atual for a de uma comunidade, como condição para a reconciliação da diversidade e do conflito, resultado do pluralismo da realidade social, com o valor racional das instituições políti-

${ }^{42}$ A crítica comunitarista ao liberalismo político de Rawls, particularmente a sua noção de comunidade é, em grande parte, e, sobretudo a de C. Taylor, de inspiração hegeliana. Ela pode ser formulada na tese principal da prevalência de uma perspectiva individualista segundo os princípios do atomismo social, pelo qual os sujeitos são portadores de direitos subjetivos a título da sua individualidade auto-explicativa. O "atomismo é um termo utilizado de modo amplo para caracterizar as doutrinas do contrato social que floresceram no século XVII, de modo que as doutrinas posteriores, sem fazer uso, necessariamente, da noção de contrato social, delas herdaram a idéia de que a sociedade é constituída, em certo sentido, pelos indivíduos, com vistas à realizar seus fins que são primeiramente individuais. [...] O termo se aplica igualmente às doutrinas contemporâneas que se voltam à teoria do contrato social, ou àquelas que querem defender, de um modo ou de outro, a prioridade do indivíduo e dos seus direitos sobre a sociedade, ou àquelas que apresentam uma concepção puramente instrumental da sociedade." (TAYLOR, L'atomisme, in: La liberté des modernes, Trad. Philippe de Lara, Paris: PUF, 1999, p. 223). Para o "atomismo", a obrigação de pertencer à sociedade é derivada do princípio mais fundamental do indivíduo ser um sujeito de direitos, deduzido da sua identidade auto-referente. Reatualizando a prioridade da Sittlichkeit hegeliana de pertencimento social que remonta a Aristóteles, Taylor volta-se para uma análise histórica na constituição dos sujeitos e das instituições sociais e políticas, cuja normatividade é dada pela construção social de um bem comunitário que tem prioridade sobre o justo, desenvolvendo a idéia da presença subjacente de valores comunitários historicamente construídos, e a conseqüente impossibilidade do abandono de necessários pressupostos culturais na constituição de uma teoria da justiça.

43 RAWLS, J. Justiça como eqüidade: uma reformulação. Trad. Claudia Berliner, São Paulo: Martins Fontes, 2003, p. 4. 
cas que podem suportar e superar essa realidade díspar e antagônica; então, tal projeto reconciliador não se aplica ao liberalismo político. Para Rawls, a sociedade democrática moderna não é uma comunidade, no sentido de "um corpo de pessoas unidas por uma mesma doutrina abrangente, ou parcialmente abrangente," afastando-se, portanto, dessa função reconciliadora (da comunidade e do pensamento político que dela resulta) que o hegelianismo e, também, o comunitarismo querem imputar à filosofia política.

Contudo, se a questão da reconciliação for vista pelo lado da tentativa de reunir posições aparentemente antagônicas e conflitantes, então a perspectiva do liberalismo hegeliano não é absurda em relação ao caráter conciliador de uma filosofia política que quer estabelecer o consenso. Não há dúvida de que o pensamento de Rawls operou com estes dois componentes tradicionais da filosofia política: o compromisso à liberdade individual - na versão da liberdade negativa corporificada no valor liberal de sustentação dos direitos e da liberdades básicas - e a afirmação da igualdade, resultando na exigência de uma distribuição mais igualitária dos recursos de que dispõe a sociedade, somente admitindo desigualdades de renda e riqueza em benefício da população menos favorecida. A presença desses dois elementos revela uma tensão entre a ênfase à liberdade individual da tradição do liberalismo, presente na prioridade que Rawls atribui ao primeiro dos seus princípios, e as exigências distributivistas e igualitaristas da sociedade, presentes no segundo princípio. Uma das metas da justiça como eqüidade é propiciar um fundamento filosófico razoável para que as instituições democráticas possam dar conta desta tensão, reconciliando as exigências da liberdade e da igualdade na perspectiva de um liberalismo (político) que permita superar esses antagonismos.

Uma outra forma de perceber a presença da função reconciliadora da filosofia política consiste em interpretar a teoria de Rawls como uma tentativa de análise de uma fundamentação filosófica das instituições políticas que regem a estrutura de base das sociedades modernas, na perspectiva política (não metafísica) inserida no quadro da tradição do liberalismo. Contra qualquer tentativa de realização moral da política, pois valores morais podem comprometer o pluralismo, conquista inamovível da democracia, Rawls elabora uma versão estritamente política e eticamente neutra da sua teoria da justiça, e tenta mostrar que o campo de aplicação de sua teoria restringe-se às sociedades liberais modernas, aquelas que têm um governo constitucional, respeitam os direitos individuais e o pluralismo, e que praticam uma economia de mercado. O liberalismo político de Rawls opera, portanto, com o procedimento metodológico da conciliação de um "certo número de idéias básicas conhecidas implícitas na cultura pública de uma sociedade democrática", ${ }^{44}$ com uma forma abstrata de representação das mesmas. Desta forma, o liberalismo político de Rawls parece ser o resultado do espelhamento normativo da sociedade liberal moderna, no sentido de construir e sistematizar as convicções básicas dessa sociedade, através de um procedimento de abstração. Esse proce-

4 RAWLS, J. Liberalismo Político, op. cit., p. 67. 
dimento se revela pelo recurso do método das "concepções-modelo" (sociedade bem ordenada, pessoa moral e posição original), operando com idéias "reguladoras" que devem se reconciliar com a realidade social e histórica das sociedades liberais modernas.

A interpretação do hegelianismo no quadro do liberalismo da liberdade estimula Rawls a avaliar com mais justeza as contribuições da teoria de Hegel. Pretende, desse modo, interpretar o hegelianismo político sob a ótica da sua teoria, procurando mostrar que as contribuições de Hegel não são absurdas ou estranhas em relação às principais teses do seu liberalismo político. O ajuste do hegelianismo a essas teses é plausível se ele for interpretado na ótica do liberalismo da liberdade e comparado com os princípios do liberalismo político. Tal ajuste permite não só "aproveitar" as contribuições hegelianas compatíveis com esse liberalismo, como também dar uma resposta às críticas comunitaristas de inspiração hegeliana, pois a unilateralidade destas críticas torna o liberalismo de Rawls impermeável aos possíveis aportes da filosofia política hegeliana.

Assim, a análise de Rawls do liberalismo da liberdade de Hegel desenvolve-se no sentido de separar o joio metafísico do trigo liberal na filosofia política hegeliana, sublinhando aquilo que é razoável para a sua teoria, sem abandonar os elementos principais que ela propõe. Essa parece ser a razão pela qual Rawls afirma que, no embate da sua teoria com o hegelianismo político, "o alegado conflito com o liberalismo parece até agora não existir." As críticas que foram enunciadas dependem, diz Rawls, de uma concepção "equivocada", de uma "paródia" do liberalismo.

\section{Referências}

BIENENSTOCK, M. Politique du jeune Hege - léna 1801-1806. Paris: PUF, 1992.

BOBBIO, N. Estudos sobre Hegel. Direito, sociedade civil, estado. Trad. Luiz S.Henriques e Carlos Nelson Coutinho. São Paulo: Unesp/Brasiliense, 1989.

CONSTANT, B. De la liberté chez les modernes. Paris: Librairie Générale Française, 1980.

GUILLARME, B. Rawls et l'égalité démocratique. Paris: PUF, 1999.

HARDIMON, M. Hegel's social philosophy. Cambridge: Cambridge University Press, 1994.

HEGEL, G. W. F. Werke in zwanzig Bänden. Eds. E. Moldenhauer e K. M. Michel. Frankfurt am Main: Suhrkamp, Taschenbuch Wissenschaft, 1986.

. Grundlinien der Philosophie des Rechts oder Naturrecht und Staatswissenschaft im Grundrisse, Werk 7. Frankfurt am Main: Suhrkamp Verlag, 1970.

Linhas fundamentais da filosofia do direito ou direito natural e ciência do estado em compêndio. Trad. Marcos Lutz Müller. Campinas: Unicamp, 1996/8. (Textos Didáticos)

Enzyklopädie der Philosophischen wissenschaften im Grundrisse. Herausgegeben von F. Nicolin e O. Pöggeler. Hamburg: Felix Meiner, 1969.

${ }^{45}$ RAWLS, J. Lectures on the History of Moral Philosophy, op. cit., p. 369. 
Encyclopédie des sciences philosophiques,I. La science de la logique. Trad. B. Bourgeois. Paris: Vrin, 1972.

HOBBES, T. O Leviatã. Trad. João Paulo Monteiro e Maria Beatriz N. da Silva. São Paulo: Abril Cultural, 1974. (Col. Os Pensadores)

ILTING, K. H. La forme logique et systématique de la philosophie du droit. In: Hegel et la philosophie du droit. Paris: PUF, 1979.

KANT, I. Métaphysique des moeurs. Doctrine du droit. Trad. A. Philonenko, Paris: Vrin, 1979.

KYMLICKA, W. Liberalism, community and culture. Oxford : Clarendon Press, 1989.

LOSURDO, D. Hegel, Marx e a tradição liberal. Liberdade, igualdade, estado. Trad. Carlo N. Dastoli, São Paulo: Fundação Ed. UNESP, 1998.

LARMORE. C. The morals of modernity. Cambridge: Cambridge University Press, 1996.

MILL, S. Sobre a liberdade. 2. ed. Trad. Alberto da Rocha Barros. Petrópolis: Vozes, 1991.

MOUFFE, C. Le libéralisme américain et ses critiques. Ralws, Taylor, Sandel, Walzer. In: Esprit, v. 3, mars 1987.

The return of the political. New York: Verso, 1993.

MULHALL, J.; SWIFT, A. Liberals and communitarians. Oxford : Blackwell, 1992.

PETTIT, P. Judging justice: an introduction to contemporary political philosophy. London: Routledge e Kegan Paul, 1980.

PINSON, J. C. Hegel, le droit et le libéralisme. Paris: PUF, 1989.

PLANTY-BONJOUR, O. Le projet hégélien. Paris: Vrin, 1993.

RAMOS, C. A. Liberdade subjetiva e estado na filosofia política de Hegel. Curitiba: Ed. UFPR, 2000.

. Hegel e o processo de auto-referencialidade da liberdade no direito natural moderno. In: Cadernos de História e Filosofia da Ciência, Campinas, série 3, v. 12, n. 1-2, jan.-dez. 2002.

RAWLS, J. Uma teoria da justiça. Trad. Almiro Pisetta e Lenita M.R. Esteves. São Paulo: Martins Fontes, 1997.

— O liberalismo político. Trad. João S. Nunes. Lisboa: Presença, 1997.

. Collected papers. Edited by Samuel Freeman. Cambridge: Harvard University Press, 1999.

— Justiça e democracia. Trad. Irene A. Paternot. São Paulo: Martins Fontes, 2000.

— Lectures on the history of moral philosophy. Cambridge: Harvard University Press, 2000.

2003.

STILLMANN, P. Hegel's critique of liberal theories of rights. In: The American Political Science Review, V. 68, p. 1086-1092, 1974.

SCHAWARZENBACH, S. Rawls, Hegel, and communitarianism. In: Political Theory, v. 19, n. 4, nov. 1991.

TAYLOR, C. Hegel and modern society. Cambridge: Cambridge Univ. Press, 1978.

. Le juste et le bien. In: Revue de Métaphysique et de Morale, 83, 1988

. Hegel's ambiguous legacy for modern liberalism. In: CORNELL, D.; ROSENFELD, M.; CARLSON, D. G. (eds.). Hegel and legal theory. London: Routledge, 1991. 
Multiculturalism. Princeton : Princeton University Press, 1994.

. La liberté des modernes. Paris: PUF, 1997.

As fontes do self. A construção da identidade moderna. Trad. Adail U. Sobral e Dinah de Abreu Azevedo. São Paulo: Loyola, 1997.

VILLEY, M. La formation de la pensée juridique moderne. Paris: Montchretien, 1975

WOOD, A. Hegel's ethical thought. Cambridge: Cambridge University Press, 1990. 